\title{
Efficacy of platelet-rich plasma and plasma for symptomatic treatment of knee osteoarthritis: a double-blinded placebo- controlled randomized clinical trial
}

\author{
Murillo Dório ${ }^{1 *}$, Rosa Maria Rodrigues Pereira ${ }^{1}$, Alexandre Galeno Branco Luz² , Leticia Alle Deveza ${ }^{3}$, \\ Ricardo Manoel de Oliveira ${ }^{2}$ and Ricardo Fuller ${ }^{1}$
}

\begin{abstract}
Background: Platelet-rich plasma (PRP) has a still conflicting efficacy for knee osteoarthritis (KOA) and might be a minimally invasive and safe treatment alternative. The potential benefit of only plasma (non-enriched) has never been investigated. Our aim was to evaluate the efficacy of intra-articular platelet-rich plasma (PRP) and plasma to improve pain and function in participants with KOA over 24 weeks.

Methods: Randomized, double-blind, placebo-controlled trial with 3 groups $(n=62)$ : PRP $(n=20)$, plasma $(n=$ $21)$ and saline $(n=21)$. Two ultrasound-guided knee injections were performed with a 2-week interval. The primary outcome was visual analog scale 0-10 cm (VAS) for overall pain at week 24, with intermediate assessments at weeks 6 and 12. Main secondary outcomes were: KOOS, OMERACT-OARSI criteria and TUGT.

Results: At baseline, $92 \%$ of participants were female, with a mean age of 65 years, mean BMl of $28.0 \mathrm{Kg} / \mathrm{m}^{2}$ and mean VAS pain of $6.2 \mathrm{~cm}$. Change in pain from baseline at week 24 were -2.9 (SD 2.5), - 2.4 (SD 2.5) and $-3.5 \mathrm{~cm}$ (SD 3.3) for PRP, plasma and saline, respectively ( $p$ intergroup $=0.499$ ). There were no differences between the three groups at weeks 6 and 12. Similarly, there were no differences between groups regarding secondary outcomes. The PRP group showed higher frequency of adverse events (65\% versus $24 \%$ and $33 \%$ for plasma and saline, respectively, $p=0.02$ ), mostly mild transitory increase in pain.
\end{abstract}

Conclusions: PRP and plasma were not superior to placebo for pain and function improvement in KOA over 24 weeks. The PRP group had a higher frequency of mild transitory increase in pain.

Trial registration: ClinicalTrials.gov, NCT03138317, 03/05/2017.

Keywords: Knee osteoarthritis, Plasma, Platelet-rich plasma, PRP

*Correspondence: murillodorio@gmail.com

${ }^{1}$ Rheumatology Division, Hospital das Clínicas da Faculdade de Medicina da Universidade de São Paulo, São Paulo, Brazil

Full list of author information is available at the end of the article

\section{Background}

Knee osteoarthritis (KOA) is estimated to affect over $10 \%$ of the population worldwide [1] with a lifetime risk of 45\% [2]. Current guidelines recommend both non-drug (such as exercise) and drug therapies (such as anti-inflammatory agents) [3, 4]. However, these therapies generally have short-term benefits and effect sizes are only small to moderate $[5,6]$. Furthermore, use of permits use, sharing, adaptation, distribution and reproduction in any medium or format, as long as you give appropriate credit to the original author(s) and the source, provide a link to the Creative Commons licence, and indicate if changes were made. The images or other third party material in this article are included in the article's Creative Commons licence, unless indicated otherwise in a credit line to the material. If material is not included in the article's Creative Commons licence and your intended use is not permitted by statutory regulation or exceeds the permitted use, you will need to obtain permission directly from the copyright holder. To view a copy of this licence, visit http://creativecommons.org/licenses/by/4.0/. The Creative Commons Public Domain Dedication waiver (http://creativeco mmons.org/publicdomain/zero/1.0/) applies to the data made available in this article, unless otherwise stated in a credit line to the data. 
drugs is restricted in patients with comorbidities due to the risk of adverse events [3]. Intra-articular glucocorticoids are generally recommended only for short-term pain relief given that benefits are limited to few weeks $[3,7]$, and a recent study suggested that repeated injections are associated with increased cartilage loss [8]. Hyaluronic acid (HA) use is controversial, and guidelines provide conditional recommendations [3, 4]. Having failed these options, knee arthroplasty is usually an effective definitive treatment, but it is expensive and there is the risk of medical and post-surgical complications [9]. Thus, identifying alternative efficacious and safe treatments for KOA is important.

Biological treatments have been recently studied for treatment of knee OA such as platelet-rich plasma (PRP) [10], an autologous blood product that contains an elevated concentration of platelets. The release of growth factors and other molecules, including platelet-derived growth factor, transforming growth factor- $\beta$, type I insulin-like growth factor and vascular endothelial growth factor is supposed to be related to its efficacy [11]. Several clinical trials have shown that PRP may be promising for KOA treatment [12-14]. However, most of them are conflicting regarding the methods and present many limitations that hinder an adequate analysis of their results, with risk of bias [13, 15]. Heterogeneity in the preparation and injection methods used by published studies is a limitation for determining optimal PRP protocols [12, 14]. Furthermore, the majority of trials has the HA as comparator, which is itself controversial [12]. A few trials compared PRP to placebo so far, with results showing significantly greater improvements in symptoms over saline at 6 and 12 months [16-20]. However, these studies suffered from major methodological flaws including lack of adequate blinding, suggesting that the benefits may have been overestimated [12]. Thus, further studies comparing PRP to placebo are still necessary.

Human plasma is composed of water, several proteins and electrolytes, coagulation factors and immunoglobulins. As it is the medium in which the concentrated platelets of the PRP are diluted, the study of its possible action for improving the outcomes in KOA is important. The advantages of PRP or plasma for treatment for KOA would be: i) it is relatively easy to use as preparation is rapid and it is minimally invasive; ii) it is a relative lowcost treatment, considering the use of existing structure and equipment in public health services; and iii) it is likely to be safe as it is an autologous product and previous studies reported only minor and transient adverse effects [12]. Therefore, the aim of this study was to evaluate the efficacy of PRP and plasma for improving pain and function in participants with KOA over 24 weeks.

\section{Methods}

\section{Study design}

Clinical trial of superiority, randomized, double-blind, placebo-controlled, parallel, with 3 groups with a 1:1:1 allocation ratio. We have compared two active treatment groups, one receiving PRP and the other receiving plasma only, with a control group that received saline. Two ultrasound-guided joint injections were performed with a 2-week interval and outcomes were evaluated at week 24, with intermediate assessments at weeks 6 and 12. We have followed the Osteoarthritis Research Society International (OARSI) recommendations for KOA trials in the conduct of this study [21]. The study protocol was registered at ClinicalTrials.gov, NCT03138317, with first date of registration 03/05/2017.

\section{Sample}

The study was carried out at the Hospital das Clinicas Rheumatology Department of the University of São Paulo (HC-FMUSP), a tertiary hospital in São Paulo, Brazil. The sample consisted of participants diagnosed with KOA in rheumatology outpatient clinics and external participants advertised by word of mouth from the community and screened by telephone and then personally at the clinic. All participants were instructed about the study and signed an informed consent form.

The following criteria were used for inclusion: 1) men and women aged 45 to 80 years; 2) fulfill criteria for KOA of the American College of Rheumatology [22]; 3) radiographic grade 2 or 3 scored by the Kellgren and Lawrence (KL) [23] in at least one knee; 4) pain from 3 to 8 $\mathrm{cm}$ in the visual analogue scale $0-10 \mathrm{~cm}$ (VAS) in at least one knee in the last week. Knee $\mathrm{x}$-rays obtained within 6 months before allocation were accepted. The knee selected for treatment was the one reported with higher pain score as reported by the participant.

Exclusion criteria were: 1) use of analgesics, non-steroidal anti-inflammatory drugs, myorelaxants and systemic glucocorticoids within one week to allocation; 2) use of slow acting drugs for OA (such as chondroitin, glucosamine, diacerein) started within 8 weeks to allocation. For participants using these drugs for longer than 8 weeks, they could be maintained until the end of the study; 3 ) corticosteroids or HA intra-articular injection in the index knee within 6 months to allocation; 4) intra-articular injection of any drug in any other joint within 1 month to allocation; 5) introduction of any medical or physical intervention for the locomotor system within the last 3 months (exercise, acupuncture, cane, orthotics etc.); 6) KL 4 in any of the knees; 7) body-mass index (BMI) $\geq 35$ $\mathrm{kg} / \mathrm{m}^{2}$; 8) fibromyalgia and inflammatory arthropathies such as rheumatoid arthritis, connective tissue diseases, microcrystalline arthropathies, spondyloarthropathies 
and infectious arthropathies; 9) symptomatic OA of hips or feet; 10) previous surgery in the index knee; 11) difference in length of lower limbs $>1 \mathrm{~cm}$; 12) skin lesion on index knee surface; 13) any blood dyscrasia (including thrombocytopenia) or use of anticoagulants; 14) other diseases: severe depression, non-controlled diabetes, decompensated cardiovascular disease, infection, immunosuppression (methotrexate up to $10 \mathrm{mg} /$ week was allowed), systemic infectious disease, symptomatic lower limb vascular disease, neurological diseases, cancer or any other conditions believed to interfere with results; 15) any sick leave or similar due to KOA.

\section{Procedures}

The screening and follow-up visits were realized at Hospital das Clinicas and all baseline clinical assessment and intervention procedures were undertaken in a private laboratory. The VAS for overall pain questionnaire was applied at screening and baseline assessments to ensure that participants continued to fulfil inclusion criteria and reduce the influence of fluctuation in pain in the screening-baseline assessment period, as recently raised by some authors [24-26]. Baseline clinical assessment consisted of self-reported questionnaires, physical examination and physical tests, and collection of blood for full blood count. Participants were also underwent to ultrasonographic assessment $[27,28]$ of the index knee at baseline before treatment administration (Additional file 1). A single radiologist with more than 20 years of experience in ultrasonography of the musculoskeletal system and interventional procedures (AGBL) performed all ultrasound evaluations and guided injections and a single investigator (MD) performed all clinical assessments.

The knee injections were ultrasound-guided, performed using the superolateral approach, $2 \mathrm{~cm}$ above and laterally to the superolateral angle of the patella using a $22 \mathrm{G}$ needle, with administration of local anesthetic (2\% lidocaine without vasoconstrictor) subcutaneously for analgesia only. Using the same needle, participants received one of the three treatments (PRP, plasma or saline) according to allocation group. A bandage (Blood Stop ${ }^{\circledR}$ ) was applied with orientation to be removed the day after the procedure. Participants were instructed to avoid exercises within 48 hours after the procedure.

Throughout the study, participants were allowed to use paracetamol in case of pain, at maximum dosage of $3 \mathrm{~g} /$ day, and to avoid the use of other medications, mainly anti-inflammatory and dipyrone (metamizole).

\section{Randomization, allocation and blinding}

A randomization list was generated in blocks of 3 by a person not involved in the study, using the version 2015a of the MATLAB Program ${ }^{\circledR}$ and the allocation generation ratio was 1:1:1. For allocation concealment, correspondent letters for each treatment group were placed into sequentially numbered opaque envelopes according to the randomization list and then were sealed. These procedures were also done by a person not involved in the study. Each participant who has consented to enter the study was destined an envelope in the sequence. Allocation of participants occurred from March 2017 to October 2017 and the assessments were completed in March 2018.

All participants were submitted to blood collection to maintain blinding. The envelopes were opened sequentially by the laboratory pharmacist who prepared treatments, not involved in the study. After the preparation of the treatment injections by the pharmacist, the syringes were covered completely (including the needle base) with a non-transparent white adhesive label only with the participant's identification and delivered to the radiologist who performed the guided injections. All researchers involved in the study including the statistician who performed the analysis were blinded. Inadvertent unblinding of the radiologist/injector (AGBL) has not been assessed although he was not involved in the assessment of outcomes or data analysis. All participants were blinded. The revelation of the treatment groups occurred only after statistical analysis and production of the main results.

\section{Preparation of PRP and plasma}

Participants were submitted to collection of $40 \mathrm{ml}$ of autologous blood by the antecubital vein in vacuum tubes (BD Vacutainer ${ }^{\circledR}$ ) of $10 \mathrm{ml}$ containing as anticoagulant the sodium citrate solution at $3.8 \%$ (Fig. 1). Tubes were submitted to double centrifugation (Cel LS3 Plus ${ }^{\circledR}$ centrifuge). The first spin was performed at $1500 \mathrm{rpm}(395$ g) lasting 12 minutes. After 10 minutes of resting, an inferior layer consisting of erythrocytes, an intermediate layer with buffy coat and a superior layer of plasma were obtained. This plasma was submitted to a second spin at $2300 \mathrm{rpm}(930 \mathrm{~g}$ ) lasting 10 minutes [29] with separation of a pellet of platelets from plasma (without platelets). At this stage, plasma was obtained for use as treatment injections; and redilution of the pellet of platelets was undertaken to obtain a PRP with approximately $1 \times 10^{6}$ platelets $/ \mathrm{mm}^{3}$ (approximately 3 times the basal platelet count) also for use as treatment injections [29]. No activation was added to PRP.

Pre-centrifugation platelet count in peripheral blood was used to estimate the final volume of PRP to maintain the concentration of $1 \times 10^{6}$ platelets $/ \mathrm{mm}^{3}$ in the injections. The final volume of injected PRP ranged from 1.4 to $5 \mathrm{ml}$ for each participant. The volume of plasma and saline were also calculated according to the count of 


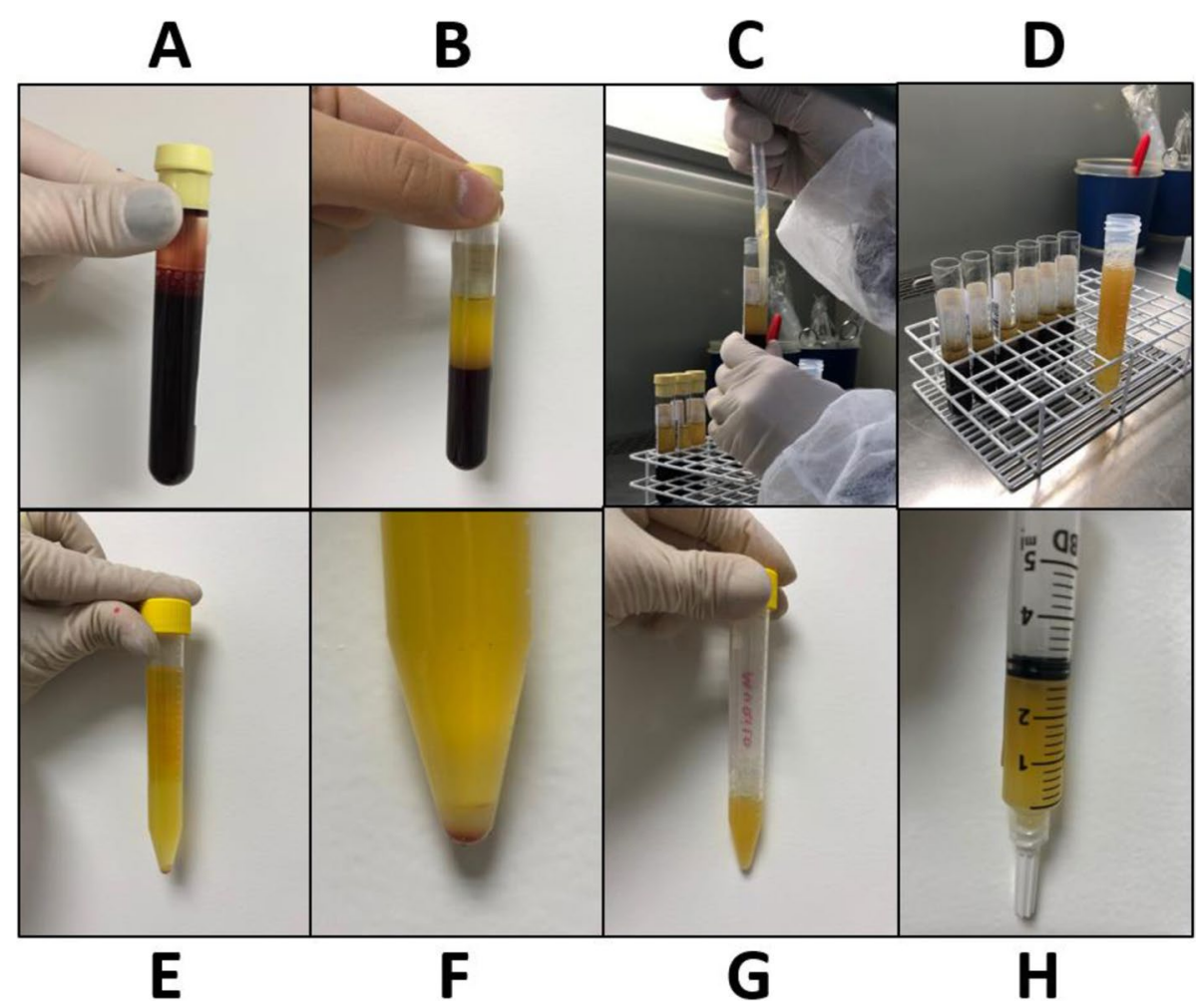

Fig. 1 Preparation of platelet-rich plasma (PRP) and plasma: A - blood collected; $\mathbf{B}$ - after $1^{\text {st }}$ centrifugation, separation of erythrocytes on the bottom, an intermediate thin layer known as buffy coat and a superior layer of plasma; $\mathbf{C}$ - separation of plasma from all tubes; $\mathbf{D}$ - separated plasma in a centrifuge tube (Falcon $\left.{ }^{\circledR}\right) ; \mathbf{E}$ - after $2^{\text {nd }}$ centrifugation, separation of a pellet of platelets on the bottom and plasma (without platelets); $\mathbf{F}$ - magnification of the pellet of platelets; $\mathbf{G}$ - plasma withdrawal (for use as treatment injections) and redilution of the pellet of platelets for obtention of a PRP with approximately $1 \times 10^{6}$ platelets $/ \mathrm{mm}^{3} ; \mathbf{H}$ - final PRP for treatment injections

platelets in peripheral blood for each participant to maintain the blinding of the radiologist who did the injections $(1.4$ to $5 \mathrm{ml})$. Platelets, leukocytes and erythrocytes were counted after centrifugations in some samples of both PRP and plasma to confirm their expected concentration. Both PRP and plasma had approximately zero leucocytes and erythrocytes. The plasma used for treatment also had approximately zero platelets.

All procedures were performed in biological-protector hoods (Veco Bioprotector ${ }^{\circledR}$ ), according to the recommendations of the Cell Medicine Society [30]. The treatments were prepared in the laboratory RDO by a single pharmacist, who works in the laboratory, not involved in the study.

\section{Outcomes}

Primary outcome was change in VAS $0-10 \mathrm{~cm}$ for overall pain in the index knee at week 24. Secondary outcomes were: 1) VAS $0-10 \mathrm{~cm}$ for pain at rest; 2) VAS $0-10 \mathrm{~cm}$ for pain at movement; 3) VAS $0-10 \mathrm{~cm}$ for physician global assessment (PhGA); 4) participant's global assessment (PGA) for improvement, 0-100\%; 5) Western
Ontario McMaster Universities Osteoarthritis Index (WOMAC), 5-point Likert 0-4 for each question [31, 32]; 6) Knee Injury and Osteoarthritis Outcome Score (KOOS), 5-point Likert 0-4 for each question [33, 34]; 7) Likert scale for improvement: no improvement, mild improvement, moderate improvement, good improvement, excellent improvement; 8) OMERACT-OARSI criteria [35] defined as A) improvement in pain or function $\geq 50 \%$ and absolute improvement $\geq 20$ or B) improvement in at least 2 of the following 3 criteria: i) pain $\geq 20 \%$ and absolute improvement $\geq 10$, ii) function $\geq 20 \%$ and absolute improvement $\geq 10$; iii) PGA $\geq 20 \%$ and absolute improvement $\geq 10$. For these criteria, pain was assessed by VAS for overall pain and function was assessed by WOMAC function subscale; 9) timed up and go test (TUGT) [36]; 10) analgesic consumption, assessed by a self-reported diary.

\section{Statistical analysis}

Sample size was calculated for the primary outcome at week 24 . A $2 \mathrm{~cm}$ reduction in VAS for overall pain was considered as the minimum difference to be detected 
between the groups with a standard deviation (SD) of 1.5 , based on the study by Patel et al [16]. An alpha of 5\% and a power of study ( 1 - beta) of $80 \%$ were used. Fifteen participants were required in each of the three groups. To allow a loss of follow-up of $20 \%$, the minimum number of participants in each group was 18. The calculation was performed by the Action Stat Pro ${ }^{\circledR}$ software.

Mean and SD were obtained for continuous variables and distribution was presented for categorical variables. To compare groups at baseline, the Chi-square or Fisher's exact tests were used for the categorical variables and ANOVA or Kruskal-Wallis for continuous variables. For data collected at 6,12 and 24 weeks, the ANOVA test with repeated measures for continuous variables. Nonparametric tests were used for evaluation of Likert scale (Friedman test for paired data) and OMERACT-OARSI criteria (Cochran's Q test for paired data). We performed a post-hoc subanalysis to investigate potential predictors of improvement with PRP or plasma treatment. The analyses were conducted using the software SPSS version 20. A statistical significance of $5 \%$ was considered for all tests and we did not adjust for multiplicity. Missing data were treated with multiple imputation.

\section{Results}

Five hundred seventy-one participants were screened and most excluded, mainly due to an end-stage KOA (KL 4) or a severe systemic disease (rheumatic or not) given that our OA clinic is at a tertiary hospital. Sixty-two participants were allocated to treatment groups (Fig. 2): 57 (92\%) were female, with mean age of 65 years and mean BMI of $28.0 \mathrm{Kg} / \mathrm{m}^{2}$. All groups were homogeneous at baseline, except for the KOOS domain for sport and recreation in which the plasma group presented higher score in relation to the PRP group, and for the presence of synovial hypertrophy in ultrasonography in which the PRP group presented lower degrees for the gray scale score in relation to the other groups (Table 1 ).

The primary outcome, VAS for overall pain at 24 weeks, demonstrated significant improvement in the 3 groups, without statistical difference between them (Fig. 3, Table 2). The mean change from baseline for overall pain

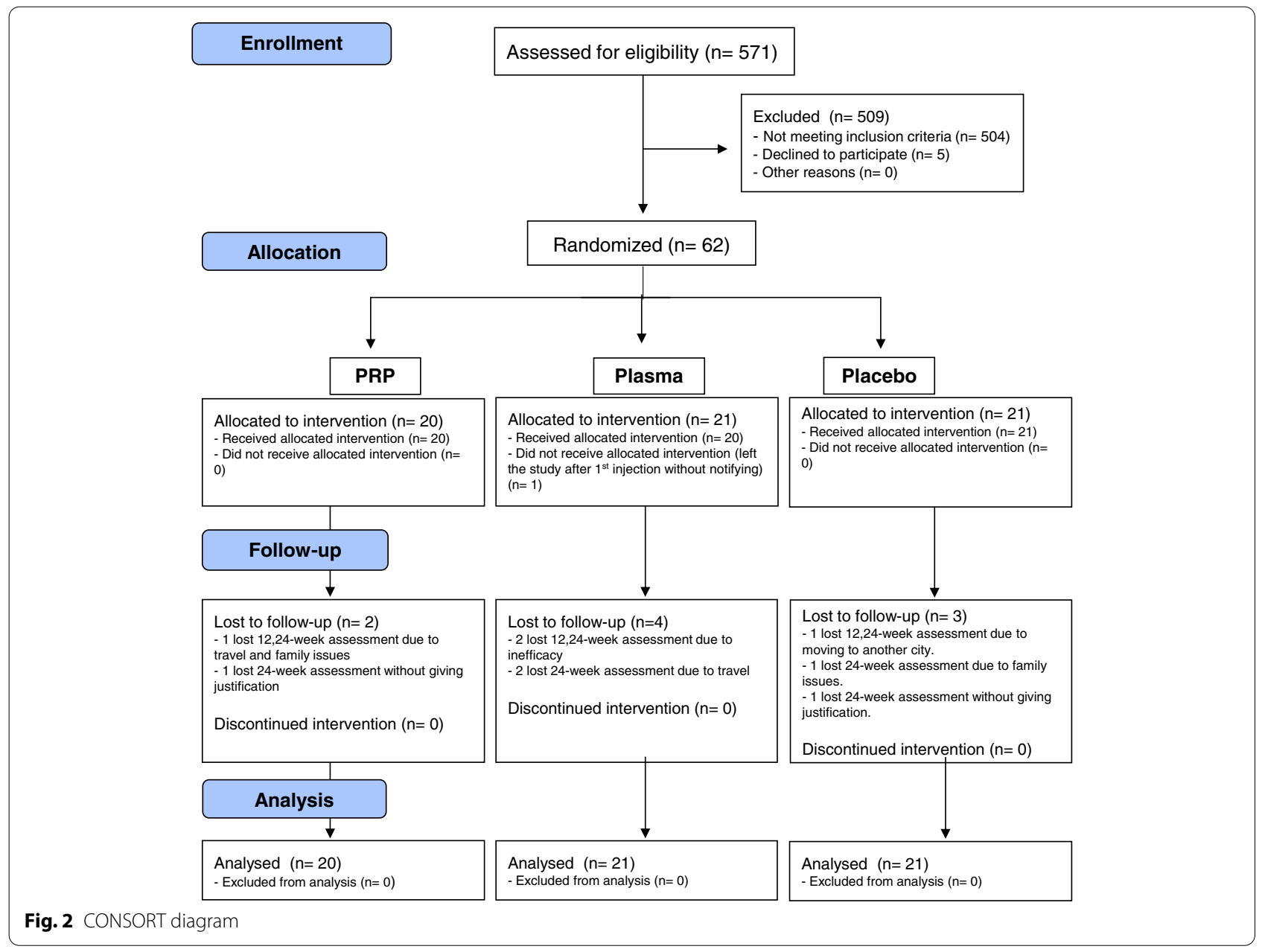


Table 1 Characteristics at baseline

\begin{tabular}{|c|c|c|c|}
\hline Variables & $\operatorname{PRP}(n=20)$ & Plasma $(n=21)$ & Placebo $(n=21)$ \\
\hline $\begin{array}{l}\text { Age in years, mean } \\
\text { (SD) }\end{array}$ & $66.4 \pm 5.6$ & $66.1 \pm 7.5$ & $62.5 \pm 8.1$ \\
\hline \multicolumn{4}{|l|}{ Sex, n (\%) } \\
\hline Male & $1(5 \%)$ & $2(10 \%)$ & $2(10 \%)$ \\
\hline Female & $19(95 \%)$ & $19(90 \%)$ & $19(90 \%)$ \\
\hline BMI, mean (SD) & $28.3 \pm 4.1$ & $28 \pm 3.1$ & $27.6 \pm 3.8$ \\
\hline \multicolumn{4}{|c|}{ BMI - category, n (\%) } \\
\hline$<25$ & $6(30 \%)$ & $4(19 \%)$ & $4(19 \%)$ \\
\hline $25-30$ & $5(25 \%)$ & $11(52 \%)$ & $11(52 \%)$ \\
\hline $30-35$ & $9(45 \%)$ & $6(29 \%)$ & $6(29 \%)$ \\
\hline \multicolumn{4}{|l|}{ Knee, n (\%) } \\
\hline Left & $9(45 \%)$ & $9(43 \%)$ & $11(52 \%)$ \\
\hline Right & $11(55 \%)$ & $12(57 \%)$ & $10(48 \%)$ \\
\hline \multicolumn{4}{|l|}{ X-ray, n (\%) } \\
\hline $\mathrm{KL} 2$ & $13(65 \%)$ & $13(62 \%)$ & $14(67 \%)$ \\
\hline KL3 & $7(35 \%)$ & $8(38 \%)$ & $7(33 \%)$ \\
\hline $\begin{array}{l}\text { Physical Activity, } \\
\text { n (\%) }\end{array}$ & $0(0 \%)$ & $0(0 \%)$ & $1(6 \%)$ \\
\hline No & $12(60 \%)$ & $9(43 \%)$ & $9(43 \%)$ \\
\hline Yes & $8(40 \%)$ & $12(57 \%)$ & $12(57 \%)$ \\
\hline \multicolumn{4}{|c|}{ Comorbidities, n (\%) } \\
\hline No & $4(20 \%)$ & $5(24 \%)$ & $3(14 \%)$ \\
\hline Yes & $16(80 \%)$ & $16(76 \%)$ & $18(86 \%)$ \\
\hline $\begin{array}{l}\text { Duration of } \\
\text { symptoms in years, } \\
\text { mean (SD) }\end{array}$ & $8.4 \pm 6.5$ & $7 \pm 8.1$ & $7.1 \pm 6.9$ \\
\hline \multicolumn{4}{|c|}{ VAS 0-10 cm for pain, mean (SD) } \\
\hline Overall & $6.1 \pm 1.6$ & $5.9 \pm 1.4$ & $6.6 \pm 1.4$ \\
\hline At rest & $2.5 \pm 2.3$ & $1.5 \pm 1.9$ & $1.9 \pm 1.9$ \\
\hline At movement & $6.8 \pm 2.1$ & $6.8 \pm 2.1$ & $6.8 \pm 2$ \\
\hline $\begin{array}{l}\text { PhGA 0-10 cm, } \\
\text { mean (SD) }\end{array}$ & $4.6 \pm 1.9$ & $4.6 \pm 1.5$ & $4.1 \pm 1.7$ \\
\hline \multicolumn{4}{|l|}{ WOMACa, mean (SD) } \\
\hline Pain $0-20$ & $10.7 \pm 3.2$ & $9.2 \pm 2.5$ & $11 \pm 3.1$ \\
\hline Stiffness 0-8 & $4.4 \pm 1.7$ & $4 \pm 1.4$ & $4.3 \pm 1.8$ \\
\hline Function 0-68 & $37.9 \pm 11.6$ & $33.5 \pm 11.2$ & $37 \pm 12$ \\
\hline Total 0-96 & $52.9 \pm 15.5$ & $46.7 \pm 14.3$ & $52.3 \pm 15.9$ \\
\hline \multicolumn{4}{|c|}{ KOOS 0-100', mean (SD) } \\
\hline Symptoms & $46.1 \pm 21$ & $56.1 \pm 21.6$ & $45.4 \pm 15.9$ \\
\hline Pain & $42.9 \pm 15.3$ & $50.8 \pm 17.5$ & $40.7 \pm 14.6$ \\
\hline $\mathrm{ADL}$ & $44.4 \pm 15.3$ & $51.8 \pm 18.6$ & $45.4 \pm 16.2$ \\
\hline $\begin{array}{l}\text { Sport/Recrea- } \\
\text { tion }\end{array}$ & $12.8 \pm 10.9$ & $29.8 \pm 21$ & $17.4 \pm 12.2$ \\
\hline QOL & $18.1 \pm 13.9$ & $29.5 \pm 16.4$ & $25 \pm 15.3$ \\
\hline $\begin{array}{l}\text { TUGT (s), mean } \\
\text { (SD) }\end{array}$ & $13.6 \pm 2.8$ & $13.8 \pm 3.1$ & $13.6 \pm 3$ \\
\hline \multicolumn{4}{|l|}{ US - synovitis, n (\%) } \\
\hline No & $6(30 \%)$ & $2(10 \%)$ & $1(5 \%)$ \\
\hline GS1 & $8(40 \%)$ & $6(29 \%)$ & $2(10 \%)$ \\
\hline GS2 & $4(20 \%)$ & $5(24 \%)$ & $7(33 \%)$ \\
\hline GS3 & $2(10 \%)$ & $8(38 \%)$ & $11(52 \%)$ \\
\hline
\end{tabular}

Table 1 (continued)

\begin{tabular}{|c|c|c|c|}
\hline Variables & $\operatorname{PRP}(n=20)$ & Plasma $(n=21)$ & Placebo $(n=21)$ \\
\hline \multicolumn{4}{|c|}{ US - power doppler, n (\%) } \\
\hline No & $16(80 \%)$ & $17(81 \%)$ & $18(86 \%)$ \\
\hline Grade 1 & $1(5 \%)$ & $3(14 \%)$ & $3(14 \%)$ \\
\hline Grade 2 & $3(15 \%)$ & $1(5 \%)$ & $0(0 \%)$ \\
\hline \multicolumn{4}{|c|}{ US - effusion, n (\%) } \\
\hline No & $6(30 \%)$ & $2(10 \%)$ & $3(14 \%)$ \\
\hline $0-2 \mathrm{~mm}$ & $2(10 \%)$ & $3(14 \%)$ & $1(5 \%)$ \\
\hline $2-4 m m$ & $5(25 \%)$ & $6(29 \%)$ & $5(24 \%)$ \\
\hline $4-6 \mathrm{~mm}$ & $4(20 \%)$ & $3(14 \%)$ & $6(29 \%)$ \\
\hline$>6 \mathrm{~mm}$ & $3(15 \%)$ & $7(33 \%)$ & $6(29 \%)$ \\
\hline \multicolumn{4}{|c|}{ US - cartilage ${ }^{c}, \mathrm{n}(\%)$} \\
\hline 1 & $0(0 \%)$ & $3(14 \%)$ & $1(5 \%)$ \\
\hline $2 \mathrm{~A}$ & $13(65 \%)$ & $8(38 \%)$ & $13(62 \%)$ \\
\hline $2 \mathrm{~B}$ & $3(15 \%)$ & $8(38 \%)$ & $4(19 \%)$ \\
\hline 3 & $4(20 \%)$ & $2(10 \%)$ & $3(14 \%)$ \\
\hline
\end{tabular}

a higher number associated with worse evaluation

${ }^{b}$ higher number associated with better evaluation

${ }^{c}$ For cartilage classification, see the text

Abbreviations: $S D$ standard deviation, $B M I$ body mass index, in $\mathrm{kg} / \mathrm{m}^{2}, K L$ Kellgren and Lawrence classification for $x$-ray, VAS visual analogue scale, $P h G A$ physician global assessment, WOMACWestern Ontario and McMaster Universities Index, KOOS Knee Injury and Osteoarthritis Outcome Score, $A D L$ function in daily living, QOL quality of life, TUGT timed up and go test; US: ultrasonography; GS: gray scale

was -2.9 (SD 2.5) cm, -2.4 (SD 2.5) $\mathrm{cm}$ and -3.5 (SD 3.3) $\mathrm{cm}$ for PRP, plasma and saline groups, respectively ( $\mathrm{p}$ intergroup $=0.499$ ). Similarly, there were no statistical differences between the groups at weeks 6 and 12 .

For almost all secondary outcomes, there were significant differences between the pre and post-treatment results, with improvement in the parameters evaluated in the 3 groups but no difference between them (Table 2). Participants in the PRP group presented significantly higher frequency of adverse events (65\% versus 25\% in the plasma group and $33 \%$ in the placebo group, $\mathrm{p}=$ 0.025 ) but without difference between groups regarding type, intensity and duration (Table 3). The most common adverse event was pain, of mild or moderate intensity, with a mean duration of 2.1 (SD 1.3) days.

It was not possible to perform the analgesic count for each group because few participants adequately completed the diaries, but there was no difference between the groups in a qualitative analysis. For all participants $(\mathrm{N}$ $=62)$, missing data occurred for $6(9.7 \%)$ participants at week 6, $7(11.3 \%)$ at week 12 and $10(16.1 \%)$ at week 24.

Complete post-hoc subanalysis are described in Additional file 2. There was no difference in the VAS for overall pain and function subscale of WOMAC in any of the subgroups analysed such as i) VAS for overall pain $<6$ versus $\geq 6 \mathrm{~cm}$ at baseline and ii) VAS for overall pain 


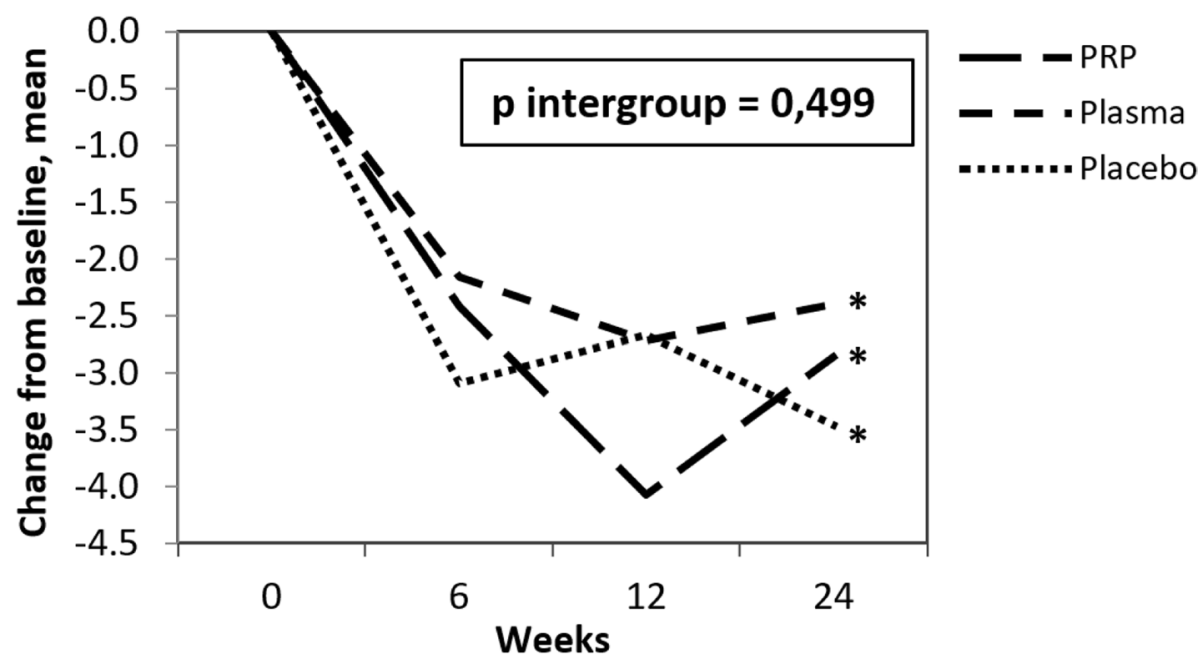

Fig. 3 Visual analogue scale $0-10 \mathrm{~cm}$ for overall pain, change from baseline. ${ }^{*} \mathrm{p}$ intragroup $<0.001$ (all 3 groups); $p<0.001$ between baseline and weeks 6,12 and $24 ; p>0.05$ between weeks 6,12 and $24.95 \%$ Confidence Intervals: PRP - week $6(-3.6 ;-1.2)$, week $12(-4.8 ;-3.4)$, week $24(-4.0 ;-1.7)$; Plasma - week $6(-3.1 ;-1.2)$, week $12(-4.0 ;-1.4)$, week $24(-3.5 ;-1.3)$; Placebo - week $6(-4.2 ;-2.0)$, week $12(-4.0 ;-1.3)$, week $24(-4.9 ;-2.1)$.

comparing two groups (PRP versus placebo; Plasma versus placebo).

\section{Discussion}

The results of this trial showed an improvement in PRP, plasma and placebo groups at weeks 6,12 and 24 for the main outcomes evaluated: VAS for overall pain, WOMAC, KOOS and OMERACT-OARSI response criteria. However, there was no difference in response between the groups over the time. Treatments were safe with only PRP group showing a higher frequency of mild transitory increase in pain in the days after injections.

A numerical and graphic difference at week 12 favoring PRP group, but without statistical significance, might suggest a beneficial effect of PRP at this timepoint. Similarly, there was a significant statistical difference in the PRP group for the likert scale for improvement from week 6 to 12 (Table 2). However, these finds should be interpreted cautiously given the lack of adjustment for multiple testing. The KOOS subscale sport/recreation also showed different results between groups with the same pattern already identified at baseline.

The current literature is divergent regarding the real effect of PRP for treatment of KOA [12]. This fact may, among other aspects, be due to the lack of standardization of the protocols across the studies, the different techniques for preparation of the PRP, and the different intervals and number of joint injections [12]. The PRP used in this study was fresh, not frozen, obtained by double centrifugation, poor in leukocytes and not activated. It contained an average of $1 \times 10^{6}$ platelets $/ \mathrm{mm}^{3}$, that is, approximately 3 times the basal platelet count in peripheral blood, applied with a 2-week interval. The advantage of fresh PRP is the theoretical decrease in the loss of function of the platelet products that may occur in the storage of frozen PRP, as was used in some studies $[18,37]$. The PRP with low concentration of leucocytes showed previous efficacy for KOA [38] with less local inflammatory reaction [39]. Activation is probably not necessary because it can be achieved through endogenous mechanisms following injection [12] and it is not supported by literature [38]. The double centrifugation might yield higher platelet concentration in PRP [40] but this is also not definitive [38]. Other studies performed a total of 1 to 4 infiltrations, with intervals ranging from 1 to 4 weeks [13, 15, 41]. Ultrasound-guided injections were a differential of our study and, by our knowledge, it was only performed by one previous study [42].

Few studies used placebo as a comparator of PRP so far, all suggesting superiority of PRP [16-20], which differed from the findings of this study. There were methodological issues in these studies such as lack of adequate blinding and use of hyaluronic acid as comparator, which cannot be considered a gold standard for the treatment of OA since there is still a divergence regarding its efficacy [41] and its effect size could have interfered in the quantification of the actual effect size of PRP.

The present study was the first, to our knowledge, to test fresh plasma (not enriched with platelets) as a therapeutic option. The justification was to evaluate whether the possible benefit of PRP demonstrated in other studies was in fact related to platelets and their products or whether there was participation of any other plasma components, such as albumin, 
Table 2 Results

\begin{tabular}{|c|c|c|c|c|c|c|}
\hline Outcomes & Groups & Baseline & Week 6 & Week 12 & Week 24 & $\begin{array}{l}\text { p-value } \\
\text { intergroup* }\end{array}$ \\
\hline \multirow[t]{3}{*}{ VAS 0-10 cm for overall pain, mean (SD) } & PRP & $6.1(1.6)$ & $3.7(2.4)$ & $2.0(1.4)$ & $3.2(2.5)$ & \multirow[t]{3}{*}{0.483} \\
\hline & Plasma & $5.9(1.4)$ & $3.7(2.5)$ & $3.2(2.8)$ & $3.5(2.4)$ & \\
\hline & Placebo & $6.6(1.4)$ & $3.5(2.1)$ & $3.9(2.7)$ & $3.1(2.6)$ & \\
\hline \multirow[t]{3}{*}{ VAS for overall pain (change from baseline), mean (SD) } & PRP & - & $-2.4(2.7)$ & $-4.1(1.6)$ & $-2.9(2.5)$ & \multirow[t]{3}{*}{0.499} \\
\hline & Plasma & - & $-2.2(2.3)$ & $-2.7(3.0)$ & $-2.4(2.5)$ & \\
\hline & Placebo & - & $-3.1(2.5)$ & $-2.7(3.2)$ & $-3.5(3.3)$ & \\
\hline \multirow[t]{3}{*}{ VAS for overall pain, \% of improvement, mean (SD) } & PRP & - & $-36.5(39.7)$ & $-67.0(23.0)$ & $-46.4(41.3)$ & \multirow[t]{3}{*}{$n s^{a}$} \\
\hline & Plasma & - & $-36.2(39.8)$ & $-43.5(55.6)$ & $-38.0(50.4)$ & \\
\hline & Placebo & - & $-43.4(46.5)$ & $-35.8(52.5)$ & $-46.5(54.3)$ & \\
\hline \multirow[t]{3}{*}{ VAS 0-10 cm for pain at rest, mean (SD) } & PRP & $2.5(2.3)$ & $1.2(1.6)$ & $0.6(0.8)$ & $1.6(2.2)$ & \multirow[t]{3}{*}{0.216} \\
\hline & Plasma & $1.5(1.9)$ & $0.8(1.1)$ & $0.6(0.7)$ & $0.9(0.9)$ & \\
\hline & Placebo & $1.9(1.9)$ & $1.6(2.0)$ & $1.0(1.2)$ & $1.4(2.3)$ & \\
\hline \multirow[t]{3}{*}{ VAS 0-10 cm for pain at movement, mean (SD) } & PRP & $6.8(2.1)$ & $4.7(2.8)$ & $3.7(2.3)$ & $3.7(2.8)$ & \multirow[t]{3}{*}{0.928} \\
\hline & Plasma & $6.8(2.1)$ & $4.5(3.1)$ & $3.9(3.1)$ & $4.0(2.7)$ & \\
\hline & Placebo & $6.8(2.0)$ & $4.2(2.2)$ & $3.9(2.9)$ & $3.5(2.6)$ & \\
\hline \multirow[t]{3}{*}{ PhGA 0-10 cm, mean (SD) } & PRP & $4.6(1.9)$ & $3.3(2.0)$ & $2.3(1.4)$ & $3.0(2.0)$ & \multirow[t]{3}{*}{0.634} \\
\hline & Plasma & $4.6(1.5)$ & $3.1(2.0)$ & $2.9(2.1)$ & $3.1(1.8)$ & \\
\hline & Placebo & $4.1(1.7)$ & $2.7(1.8)$ & $2.5(1.5)$ & $2.7(2.0)$ & \\
\hline \multirow[t]{3}{*}{ PGA (0-100\%), mean (SD) } & PRP & - & $48.0(29.9)$ & $67.3(21.6)$ & $56.3(29.2)$ & \multirow[t]{3}{*}{0.639} \\
\hline & Plasma & - & $59.0(25.3)$ & $63.2(24.5)$ & $67.7(18.8)$ & \\
\hline & Placebo & - & $59.0(27.0)$ & $57.7(31.1)$ & $66.7(25.4)$ & \\
\hline \multirow[t]{15}{*}{ Likert for global improvement ${ }^{b}, \%$} & PRP & - & $0-10 \%$ & $0-0 \%$ & $0-5 \%$ & \multirow[t]{15}{*}{$n s^{c}$} \\
\hline & & & $1-15 \%$ & $1-5 \%$ & $1-20 \%$ & \\
\hline & & & $2-25 \%$ & $2-20 \%$ & $2-15 \%$ & \\
\hline & & & $3-45 \%$ & $3-60 \%$ & $3-35 \%$ & \\
\hline & & & $4-5 \%$ & $4-15 \%$ & $4-25 \%$ & \\
\hline & Plasma & - & $0-5 \%$ & $0-0 \%$ & $0-0 \%$ & \\
\hline & & & $1-10 \%$ & $1-15 \%$ & $1-5 \%$ & \\
\hline & & & $2-35 \%$ & $2-20 \%$ & $2-40 \%$ & \\
\hline & & & $3-45 \%$ & $3-50 \%$ & $3-35 \%$ & \\
\hline & & & $4-5 \%$ & $4-15 \%$ & $4-20 \%$ & \\
\hline & Placebo & - & $0-10 \%$ & $0-14 \%$ & $0-5 \%$ & \\
\hline & & & $1-10 \%$ & $1-10 \%$ & $1-14 \%$ & \\
\hline & & & $2-33 \%$ & $2-19 \%$ & $2-5 \%$ & \\
\hline & & & $3-38 \%$ & $3-48 \%$ & $3-67 \%$ & \\
\hline & & & $4-10 \%$ & $4-10 \%$ & $4-10 \%$ & \\
\hline \multirow[t]{3}{*}{ WOMAC Pain 0-20, mean (SD) } & PRP & $10.7(3.2)$ & $7.9(3.7)$ & $5.6(2.6)$ & $6.6(3.5)$ & \multirow[t]{3}{*}{0.561} \\
\hline & Plasma & $9.2(2.5)$ & $6.8(3.6)$ & $6.1(3.9)$ & $6.5(3.6)$ & \\
\hline & Placebo & $11.0(3.1)$ & $7.4(3.5)$ & $7.1(2.8)$ & $6.2(2.3)$ & \\
\hline \multirow[t]{3}{*}{ WOMAC stiffness 0-8, mean (SD) } & PRP & $4.4(1.7)$ & $2.8(1.7)$ & $2.1(1.0)$ & $2.7(1.6)$ & \multirow[t]{3}{*}{0.713} \\
\hline & Plasma & $4.0(1.4)$ & $2.9(1.7)$ & $2.6(1.9)$ & $2.5(1.7)$ & \\
\hline & Placebo & $4.3(1.8)$ & $2.8(1.6)$ & $3.0(1.5)$ & $2.8(1.5)$ & \\
\hline \multirow[t]{3}{*}{ WOMAC function 0-68, mean (SD) } & PRP & $37.9(11.6)$ & $25.8(12.0)$ & $21.2(9.8)$ & $23.5(14.3)$ & 0.847 \\
\hline & Plasma & $33.5(11.2)$ & $25.4(13.9)$ & $20.9(14.6)$ & $24.2(15.5)$ & \\
\hline & Placebo & $37.0(12.0)$ & $26.6(12.5)$ & $24.7(10.0)$ & $22.6(11.0)$ & \\
\hline WOMAC Total 0-96, mean (SD) & PRP & $52.9(15.5)$ & $36.4(16.7)$ & $28.9(12.6)$ & $32.7(18.9)$ & 0.787 \\
\hline & Plasma & $46.7(14.3)$ & $35.0(18.5)$ & $29.6(19.9)$ & $33.2(20.3)$ & \\
\hline & Placebo & $52.3(15.9)$ & $36.9(17.1)$ & $34.9(13.5)$ & $31.6(14.4)$ & \\
\hline
\end{tabular}


Table 2 (continued)

\begin{tabular}{|c|c|c|c|c|c|c|}
\hline Outcomes & Groups & Baseline & Week 6 & Week 12 & Week 24 & $\begin{array}{l}\text { p-value } \\
\text { intergroup* }\end{array}$ \\
\hline \multirow[t]{3}{*}{ KOOS Symptoms 0-100, mean (SD) } & PRP & $46.1(21.0)$ & $67.0(19.0)$ & $71.4(13.2)$ & $63.9(21.2)$ & 0.442 \\
\hline & Plasma & $56.1(21.6)$ & $66.3(18.1)$ & $69.4(20.0)$ & $66.0(23.6)$ & \\
\hline & Placebo & $45.4(15.9)$ & $63.6(15.8)$ & $59.9(17.1)$ & $65.3(17.4)$ & \\
\hline \multirow[t]{3}{*}{ KOOS Pain 0-100, mean (SD) } & PRP & $42.9(15.3)$ & $63.9(18.7)$ & $67.6(12.5)$ & $62.4(20.1)$ & 0.434 \\
\hline & Plasma & $40.8(17.5)$ & $61.9(19.3)$ & $67.5(21.9)$ & $66.1(21.0)$ & \\
\hline & Placebo & $40.7(14.6)$ & $58.7(13.9)$ & $59.4(16.2)$ & $66.1(16.7)$ & \\
\hline \multirow[t]{3}{*}{ KOOS ADL 0-100, mean (SD) } & PRP & $44.4(15.3)$ & $64.3(18.3)$ & $68.3(17.0)$ & $64.0(20.7)$ & 0.607 \\
\hline & Plasma & $51.8(18.6)$ & $65.9(19.0)$ & $70.4(21.8)$ & $67.7(19.7)$ & \\
\hline & Placebo & $45.4(16.2)$ & $62.0(16.0)$ & $63.3(15.4)$ & $68.6(16.7)$ & \\
\hline \multirow[t]{3}{*}{ KOOS Sport/Recreation 0-100, mean (SD) } & PRP & $12.8(10.9)$ & $27.8(19.0)$ & $35.5(21.0)$ & $32.8(21.1)$ & $0.031^{d}$ \\
\hline & Plasma & $29.8(21.0)$ & $38.8(27.8)$ & $51.7(30.3)$ & $46.0(25.2)$ & \\
\hline & Placebo & $17.4(12.2)$ & $33.8(20.7)$ & $35.7(16.4)$ & $40.7(21.6)$ & \\
\hline \multirow[t]{3}{*}{ KOOS QOL 0-100, mean (SD) } & PRP & $18.1(13.9)$ & $33.1(21.4)$ & $48.1(22.0)$ & $39.1(22.4)$ & 0.336 \\
\hline & Plasma & $29.5(16.4)$ & $42.3(25.4)$ & $51.5(27.5)$ & $45.2(22.7)$ & \\
\hline & Placebo & $25.0(15.3)$ & $39.0(20.2)$ & $43.2(16.9)$ & $50.6(22.7)$ & \\
\hline \multirow[t]{3}{*}{ OMERACT-OARSI Criteria, \% } & PRP & - & $75 \%$ & $95 \%$ & $80 \%$ & $n s^{e}$ \\
\hline & Plasma & - & $70 \%$ & $85 \%$ & $80 \%$ & \\
\hline & Placebo & - & $81 \%$ & $76 \%$ & $86 \%$ & \\
\hline \multirow[t]{3}{*}{ TUGT (s), mean (SD) } & PRP & $13.6(2.8)$ & $13.0(3.2)$ & $11.6(1.6)$ & $11.5(1.3)$ & 0.866 \\
\hline & Plasma & $13.8(3.1)$ & $12.1(2.7)$ & $12.2(3.0)$ & $12.2(3.0)$ & \\
\hline & Placebo & 13.6 (3.0) & $12.3(2.7)$ & $11.4(2.0)$ & $11.4(2.4)$ & \\
\hline
\end{tabular}

* This p-value represents difference between groups; there was a statistically significant difference intragroup for all baseline parameters in relation to 6,12 and 24 weeks

a P-value intergroup week 6: $p=0.823$; week 12: $p=0.162 ;$ week 24: $p=0.814$

b 0 - no improvement; 1 - mild improvement; 2 - moderate improvement; 3 -good improvement; 4 - excellent improvement

c P-value intergroup week $6: p=0.986$; week 12: $p=0.712$; week 24: $p=0.076$. There was a significant difference in the PRP group between weeks 6 and 12 ( $p=$ 0.003 ) suggesting better responses in week 12

$d$ The difference occurred due to difference between groups PRP and plasma $(p=0.03)$ from week 6 to week $12(p=0.005)$

e P-value intergroup week 6: $\mathrm{p}=0.767$; week 12: $\mathrm{p}=0.268$; week 24: $\mathrm{p}=0.872$

Abbreviations: VAS visual analogue scale 0-10 cm, SD standard deviation; ns: no statistical significance, PhGA physician global assessment 0-10 cm, $P G A$ participant's global assessment for improvement, WOMAC Western Ontario McMaster Universities Osteoarthritis Index, KOOS Knee Injury and Osteoarthritis Outcome Score, ADL function in daily living, QOL quality of life, TUGT timed up and go test

coagulation factors, immunoglobulins, electrolytes etc. Autologous conditioned serum, for example, had already been tested for the treatment of KOA due to its anti-inflammatory properties with positive results [43].

The high rate of placebo response in OA treatment trials is a frequent issue that hinders the evaluation of treatments response [44]. It has been reported to occur in around $30 \%$ of participants [40], but some studies have reported higher values [45], such as [44] a landmark study of glucosamine and chondroitin for treatment of knee OA, which identified $60 \%$ of placebo response [42]. In the present study, the placebo response was around $50 \%$ which was likely due to contextual factors related to the close contact of participants with the single researcher who did the enrollment and assessments [46]. Furthermore, it is known that invasive treatments such as injections determine higher placebo responses than oral or topical agents [44].

The improvement in outcomes with saline makes us question whether improvement was due to the placebo effect or whether there is a possible analgesic effect of saline, as has been recently suggested in some reviews and meta-analysis [47-49]. In this regard, saline might have been a confounding factor in several clinical trials in which it was used as a placebo comparator and influenced the divergence of results, although a first trial found no difference between saline and a sham procedure for KOA pain and function in 24 weeks [50]. The mechanism of action of saline could be related to alteration of osmolality in synovial fluid and to a possible participation of sodium in the pathophysiology of OA [47, 51]. Further future studies comparing saline with a sham procedure may help to elucidate this issue. 
Table 3 Summary of all related adverse events

\begin{tabular}{|c|c|c|c|c|}
\hline Adverse events, $n$ (\%) & $\operatorname{PRP}(n=20)$ & Plasma $(n=21)$ & Placebo $(n=21)$ & p-value \\
\hline No & $7(35 \%)$ & $16(76 \%)$ & $14(67 \%)$ & 0.025 \\
\hline Yes & $13(65 \%)$ & $5(24 \%)$ & $7(33 \%)$ & \\
\hline SAES & $0(0 \%)$ & $0(0 \%)$ & $0(0 \%)$ & - \\
\hline Deaths & $0(0 \%)$ & $0(0 \%)$ & $0(0 \%)$ & - \\
\hline TEAEs, n (\%) & & & & 0.914 \\
\hline Application site pain & $8(40 \%)$ & $5(24 \%)$ & $5(24 \%)$ & \\
\hline Index knee swelling & $1(5 \%)$ & $0(0 \%)$ & $1(5 \%)$ & \\
\hline Application site pain and index knee swelling & $3(15 \%)$ & $0(0 \%)$ & $1(5 \%)$ & \\
\hline Index knee stiffness & $1(5 \%)$ & $0(0 \%)$ & $0(0 \%)$ & \\
\hline Application site ecchymosis/Bleeding & $0(0 \%)$ & $0(0 \%)$ & $0(0 \%)$ & \\
\hline Pain intensity, n (\%) & & & & 0.202 \\
\hline 0 - Mild $(0$ to $<3)$ & $6(30 \%)$ & $2(10 \%)$ & $4(19 \%)$ & \\
\hline 1 - Moderate (3 to 8) & $7(35 \%)$ & $2(10 \%)$ & $1(5 \%)$ & \\
\hline 2 - Intense (> 8 to 10$)$ & $0(0 \%)$ & $1(5 \%)$ & $2(10 \%)$ & \\
\hline Duration of pain in days, mean (SD) & $2.1 \pm 1.3$ & $2.2 \pm 1.1$ & $3.6 \pm 2.9$ & 0.681 \\
\hline
\end{tabular}

Abbreviations: PRP platelet-rich plasma, TEAEs treatment-emergent adverse events, SD standard deviation

Adverse effects were twice more frequent in the PRP group compared to the other groups. The most frequent adverse effect reported was mild to moderate increase in knee pain with a mean duration of 2 days. These results were similar to those described by other clinical trials [41].

An important limitation of this study is the relatively small sample, which may have contributed to the absence of difference between the groups. Although we have calculated the sample size using adequate methodology and previously reported SD (1.5 as described by Patel et al [16]), our results showed substantially higher SD (2.5 to 3.3), which may have limited the ability of the study to find differences. In addition, the primary outcome at week 12 might have improved the ability of finding a beneficial effect of PRP in our trial, although previous positive results were showed for 6 to 12 months [16-18].

Other limitations may be pointed out in this study. First, the total volume of injected PRP (1.4 to $5 \mathrm{ml}$ ) was variable and lower than that used in other studies [15], which might have influenced the PRP efficacy assessment. However, the PRP concentration was the same in all participants and the final absolute platelet count was similar to that injected by Patel et al [16]. It is important to note that there was no guiding standardization for PRP preparation in the literature when the trial was designed [38]. Second, participants were not recommended to washout analgesics before study visits although this is expected to be similar given participants were randomly allocated into one of the study groups. Third, the eligibility criteria were strict in order to assess the effect of PRP and $92 \%$ of sample were female, which may limit generalisability. Fourth, we have not performed joint aspiration before the PRP injection in those with joint effusion, although the benefits of this procedure in KOA have not been well established [52, 53]. Finally, we have not done a follow up ultrasonography at the end of the study, which could evaluate the effect of PRP or plasma on structural parameters, such as synovitis, joint effusion and cartilage damage.

\section{Conclusions}

A poor-leucocyte obtained by double centrifugation PRP, injected with a 2-week interval, and plasma were not superior to placebo for pain and function improvement in KOA over 24 weeks, although the relatively small sample may have influenced this finding. The PRP group had a higher frequency of mild transitory increase in pain. Future research comparing PRP to placebo is necessary to confirm the results of this study.

\section{Abbreviations}

BMI: Body-mass index; HA: Hyaluronic acid; KL: Kellgren and Lawrence; KOA: Knee osteoarthritis; KOOS: Knee Injury and Osteoarthritis Outcome Score; PGA: Participant's global assessment; PhGA: Physician global assessment; PRP: Platelet-rich plasma; SD: Standard deviation; TUGT: Timed up and go test; VAS: Visual analogue scale; WOMAC: Western Ontario McMaster Universities Osteoarthritis Index.

\section{Supplementary Information}

The online version contains supplementary material available at https://doi. org/10.1186/s12891-021-04706-7.

Additional file 1.

Additional file 2. 


\section{Acknowledgements}

We thank i) Dr Luiz Eduardo de Paula for the early version of the study protocol; ii) Pharmacist Walquiria Tavares Gomes Rosendo for preparation of treatments and helping with allocation of participants and blinding; iii) Danielle Daffre, for the statistical analysis; iv) Prof Marco Demange, Dr Jamil Natour and Dr Rita Furtado for suggestions regarding methodology and presentation of data; v) Prof David Hunter, Dr Jillian Eyles, Dr Jocelyn Bowden and all team from the Kolling Institute of the University of Sydney for suggestions regarding methodology, presentation and discussion of results; vi) Roberto Bozzi for transporting the participants during the study assessments.

\section{Authors' contributions}

$M D, R M R P, R D O$ and RF participated in the conception and design of the study. MD and AGBL contributed to acquisition of data. MD, LAD, RMRP and RF contributed to data analysis. All authors contributed to interpretation of the data, drafting and revision of the manuscript. All authors read and approved the final manuscript.

\section{Funding}

There was no funding for this study. The laboratory RDO donated the necessary material used for injections and PRP preparation.

\section{Availability of data and materials}

The datasets used and analysed during the current study are available from the corresponding author on reasonable request.

\section{Declarations}

\section{Ethics approval and consent to participate}

This study was approved by the ethics committee of the Hospital das Clínicas of the University of São Paulo: Comissão de Ética para Análise de Projetos de Pesquisa (CAPPesq), with registration number 15059, approved on $08 / 06 / 2016$. The procedures used in this study adhere to the tenets of the Declaration of Helsinki. All participants were instructed about the procedure and method of the study and signed an informed consent form.

\section{Consent for publication}

Not applicable.

\section{Competing interests}

The authors declare that they have no competing interests.

\section{Author details}

${ }^{1}$ Rheumatology Division, Hospital das Clínicas da Faculdade de Medicina da Universidade de São Paulo, São Paulo, Brazil. ${ }^{2}$ RDO Diagnósticos Médicos, São Paulo, Brazil. ${ }^{3}$ Rheumatology Department, Royal North Shore Hospital and Institute of Bone and Joint Research, Kolling Institute, University of Sydney, Sydney, New South Wales, Australia.

Received: 11 May 2021 Accepted: 10 August 2021

Published online: 24 September 2021

\section{References}

1. Lawrence RC, Felson DT, Helmick CG, Arnold LM, Choi H, Deyo RA, et al. Estimates of the prevalence of arthritis and other rheumatic conditions in the United States. Part II. Arthritis Rheum. 2008;58(1):26-35.

2. Losina E, Weinstein AM, Reichmann WM, Burbine SA, Solomon DH, Daigle $M E$, et al. Lifetime risk and age at diagnosis of symptomatic knee osteoarthritis in the US. Arthritis Care Res. 2013;65(5):703-11.

3. Bannuru RR, Osani MC, Vaysbrot EE, Arden NK, Bennell K, Bierma-Zeinstra SMA, et al. OARSI guidelines for the non-surgical management of knee, hip, and polyarticular osteoarthritis. Osteoarthr Cartil. 2019;27(11):157889. https://doi.org/10.1016/j.joca.2019.06.011. Epub 2019 Jul 3.

4. Bruyère $\mathrm{O}$, Honvo G, Veronese N, Arden NK, Branco J, Curtis EM, et al. An updated algorithm recommendation for the management of knee osteoarthritis from the European Society for Clinical and Economic Aspects of Osteoporosis, Osteoarthritis and Musculoskeletal Diseases (ESCEO).
Semin Arthritis Rheum. 2019;49(3):337-50. https://doi.org/10.1016/j. semarthrit.2019.04.008. Epub 2019 Apr 30.

5. Machado GC, Maher CG, Ferreira PH, Pinheiro MB, Lin CW, Day RO, et al. Efficacy and safety of paracetamol for spinal pain and osteoarthritis: systematic review and meta-analysis of randomised placebo controlled trials. BMJ. 2015;350:h1225.

6. Fransen M, McConnell S, Harmer AR, Van der Esch M, Simic M, Bennell KL. Exercise for osteoarthritis of the knee. Cochrane Database Syst Rev. 2015;1:CD004376.

7. Nelson AE, Allen KD, Golightly YM, Goode AP, Jordan JM. A systematic review of recommendations and guidelines for the management of osteoarthritis: The chronic osteoarthritis management initiative of the U.S bone and joint initiative. Semin Arthritis Rheum. 2014;43(6):701-12.

8. McAlindon TE, LaValley MP, Harvey WF, Price LL, Driban JB, Zhang M, et al. Effect of Intra-articular Triamcinolone vs Saline on Knee Cartilage Volume and Pain in Patients With Knee Osteoarthritis: A Randomized Clinical Trial. JAMA. 2017;317(19):1967-75.

9. Hunter DJ, Bierma-Zeinstra S. Osteoarthritis. Lancet. 2019;393(10182):1745-59.

10. Demange MK, Sisto M, Rodeo S. Future trends for unicompartmental arthritis of the knee: injectables \& stem cells. Clin Sports Med. 2014;33(1):161-74

11. Zhu Y, Yuan M, Meng HY, Wang AY, Guo QY, Wang Y, et al. Basic science and clinical application of platelet-rich plasma for cartilage defects and osteoarthritis: a review. Osteoarthr Cartil. 2013;21(11):1627-37.

12. Bennell KL, Hunter DJ, Paterson KL. Platelet-Rich Plasma for the Management of Hip and Knee Osteoarthritis. Curr Rheumatol Rep. 2017;19(5):24.

13. Shen $L$, Yuan T, Chen S, Xie X, Zhang C. The temporal effect of plateletrich plasma on pain and physical function in the treatment of knee osteoarthritis: systematic review and meta-analysis of randomized controlled trials. J Orthop Surg Res. 2017;12(1):16.

14. Knop E, Paula LE, Fuller R. Platelet-rich plasma for osteoarthritis treatment. Rev Bras Reumatol Engl Ed. 2016;56(2):152-64.

15. Zhang HF, Wang CG, Li H, Huang YT, Li ZJ. Intra-articular platelet-rich plasma versus hyaluronic acid in the treatment of knee osteoarthritis: a meta-analysis. Drug Des Devel Ther. 2018;12:445-53.

16. Patel S, Dhillon MS, Aggarwal S, Marwaha N, Jain A. Treatment with platelet-rich plasma is more effective than placebo for knee osteoarthritis: a prospective, double-blind, randomized trial. Am J Sports Med. 2013;41(2):356-64

17. Smith PA. Intra-articular Autologous Conditioned Plasma Injections Provide Safe and Efficacious Treatment for Knee Osteoarthritis: An FDASanctioned, Randomized, Double-blind, Placebo-controlled Clinical Trial. Am J Sports Med. 2016;44(4):884-91.

18. Görmeli G, Görmeli CA, Ataoglu B, Çolak C, Aslantürk O, Ertem K. Multiple PRP injections are more effective than single injections and hyaluronic acid in knees with early osteoarthritis: a randomized, doubleblind, placebo-controlled trial. Knee Surg Sports Traumatol Arthrosc. 2017;25(3):958-65.

19. Lin $\mathrm{KY}$, Yang CC, Hsu CJ, Yeh ML, Renn JH. Intra-articular Injection of Platelet-Rich Plasma Is Superior to Hyaluronic Acid or Saline Solution in the Treatment of Mild to Moderate Knee Osteoarthritis: A Randomized, Double-Blind, Triple-Parallel. Placebo-Controlled Clinical Trial Arthroscopy. 2019;35(1):106-17.

20. Elik H, Doğu B, Yılmaz F, Begoğlu FA, Kuran B. The efficiency of plateletrich plasma treatment in patients with knee osteoarthritis. J Back Musculoskelet Rehabil. 2020;33(1):127-38.

21. McAlindon TE, Driban JB, Henrotin Y, Hunter DJ, Jiang GL, Skou ST, et al. OARSI Clinical Trials Recommendations: Design, conduct, and reporting of clinical trials for knee osteoarthritis. Osteoarthr Cartil. 2015;23(5):747-60.

22. Altman R, Asch E, Bloch D, Bole G, Borenstein D, Brandt K, et al. Development of criteria for the classification and reporting of osteoarthritis. Classification of osteoarthritis of the knee. Diagnostic and Therapeutic Criteria Committee of the American Rheumatism Association. Arthritis Rheum. 1986;29(8):1039-49.

23. KELLGREN JH, LAWRENCE JS. Radiological assessment of osteo-arthrosis. Ann Rheum Dis. 1957;16(4):494-502.

24. Treister R, Honigman L, Lawal OD, Lanier RK, Katz NP. A deeper look at pain variability and its relationship with the placebo response: results 
from a randomized, double-blind, placebo-controlled clinical trial of naproxen in osteoarthritis of the knee. Pain. 2019;160(7):1522-8.

25. Guehring H, Moreau F, Daelken B, Ladel C, Guenther O, Bihlet AR, et al. The effects of sprifermin on symptoms and structure in a subgroup at risk of progression in the FORWARD knee osteoarthritis trial. Semin Arthritis Rheum. 2021;51(2):450-6.

26. Bihlet AR, Byrjalsen I, Simon LS, Carrara D, Delpy L, Derne C. A novel diclofenac gel (AMZ001) applied once or twice daily in subjects with painful knee osteoarthritis: A randomized, placebo-controlled clinical trial. Semin Arthritis Rheum. 2020;50(6):1203-13.

27. D'Agostino MA, Conaghan P, Le Bars M, Baron G, Grassi W, Martin-Mola E, et al. EULAR report on the use of ultrasonography in painful knee osteoarthritis. Part 1: prevalence of inflammation in osteoarthritis. Ann Rheum Dis. 2005;64(12):1703-9.

28. Saarakkala S, Waris P, Waris V, Tarkiainen I, Karvanen E, Aarnio J, et al. Diagnostic performance of knee ultrasonography for detecting degenerative changes of articular cartilage. Osteoarthr Cartil. 2012;20(5):376-81.

29. Akhundov K, Pietramaggiori G, Waselle L, Darwiche S, Guerid S, Scaletta C, et al. Development of a cost-effective method for platelet-rich plasma (PRP) preparation for topical wound healing. Ann Burns Fire Disasters. 2012;25(4):207-13.

30. International Cellular Medicine Society. Platelet Rich Plasma (PRP) Guidelines. 2011. Available from: http://www.cellmedicinesociety.org/ attachments/370_Section\%2010\%20-\%20Platelet\%20Rich\%20Plasma\% 20(PRP)\%20Guidelines.pdf.

31. Bellamy N, Buchanan WW, Goldsmith CH, Campbell J, Stitt LW. Validation study of WOMAC: a health status instrument for measuring clinically important patient relevant outcomes to antirheumatic drug therapy in patients with osteoarthritis of the hip or knee. J Rheumatol. 1988;15(12):1833-40.

32. Lage PTS, Machado LAC, Barreto SM, de Figueiredo RC, Telles RW. Measurement properties of Portuguese-Brazil Western Ontario and McMaster Universities osteoarthritis index (WOMAC) for the assessment of knee complaints in Brazilian adults: ELSA-Brasil Musculoskeletal cohort. Rheumatol Int. 2020;40(2):233-42. https://doi.org/10.1007/s00296-019-044961. Epub 2019 Dec 19.

33. Roos EM, Roos HP, Lohmander LS, Ekdahl C, Beynnon BD. Knee Injury and Osteoarthritis Outcome Score (KOOS)--development of a self-administered outcome measure. J Orthop Sports Phys Ther. 1998;28(2):88-96.

34. Almeida GPL. Translation and cross-cultural validation of the KOOS to Brazilian Portuguese. 2016. Available from: http://www.koos.nu/.

35. Pham T, Van Der Heijde D, Lassere M, Altman RD, Anderson JJ, Bellamy N, et al. Outcome variables for osteoarthritis clinical trials: The OMERACTOARSI set of responder criteria. J Rheumatol. 2003;30(7):1648-54.

36. Podsiadlo D, Richardson S. The timed "Up \& Go": a test of basic functional mobility for frail elderly persons. J Am Geriatr Soc. 1991;39(2):142-8.

37. Filardo G, Di Matteo B, Di Martino A, Merli ML, Cenacchi A, Fornasari P, et al. Platelet-Rich Plasma Intra-articular Knee Injections Show No Superiority Versus Viscosupplementation: A Randomized Controlled Trial. Am J Sports Med. 2015;43(7):1575-82.

38. Amin I, Gellhorn AC. Platelet-Rich Plasma Use in Musculoskeletal Disorders: Are the Factors Important in Standardization Well Understood? Phys Med Rehabil Clin N Am. 2019;30(2):439-49.

39. Filardo G, Kon E, Pereira Ruiz MT, Vaccaro F, Guitaldi R, Di Martino A, et al Platelet-rich plasma intra-articular injections for cartilage degeneration and osteoarthritis: single- versus double-spinning approach. Knee Surg Sports Traumatol Arthrosc. 2012;20(10):2082-91.
40. Fukaya M, Ito A. A New Economic Method for Preparing Platelet-rich Plasma. Plast Reconstr Surg Glob Open. 2014;2(6):e162.

41. Di Y, Han C, Zhao L, Ren Y. Is local platelet-rich plasma injection clinically superior to hyaluronic acid for treatment of knee osteoarthritis? A systematic review of randomized controlled trials. Arthritis Res Ther. 2018;20(1):128.

42. Ahmad HS, Farrag SE, Okasha AE, Kadry AO, Ata TB, Monir AA, et al. Clinical outcomes are associated with changes in ultrasonographic structural appearance after platelet-rich plasma treatment for knee osteoarthritis. Int J Rheum Dis. 2018;21(5):960-6.

43. Wehling P, Moser C, Frisbie D, Mcllwraith CW, Kawcak CE, Krauspe R, et al. Autologous conditioned serum in the treatment of orthopedic diseases: the orthokine therapy. BioDrugs. 2007;21(5):323-32.

44. Zhang W, Robertson J, Jones AC, Dieppe PA, Doherty M. The placebo effect and its determinants in osteoarthritis: meta-analysis of randomised controlled trials. Ann Rheum Dis. 2008:67(12):1716-23.

45. Altman RD, Moskowitz R. Intraarticular sodium hyaluronate (Hyalgan) in the treatment of patients with osteoarthritis of the knee: a randomized clinical trial. Hyalgan Study Group. J Rheumatol. 1998;25(11):2203-12.

46. Nielsen SM, Tugwell P, de Wit MPT, Boers M, Beaton DE, Woodworth TG, et al. Identifying Provisional Generic Contextual Factor Domains for Clinical Trials in Rheumatology: Results from an OMERACT Initiative. J Rheumatol. 2019;46(9):1159-63.

47. Bar-Or D, Rael LT, Brody EN. Use of Saline as a Placebo in Intra-articular Injections in Osteoarthritis: Potential Contributions to Nociceptive Pain Relief. Open Rheumatol J. 2017;11:16-22.

48. Saltzman BM, LerouxT, Meyer MA, Basques BA, Chahal J, Bach BR, et al. The Therapeutic Effect of Intra-articular Normal Saline Injections for Knee Osteoarthritis: A Meta-analysis of Evidence Level 1 Studies. Am J Sports Med. 2017:45(11):2647-53.

49. Altman RD, Devji T, Bhandari M, Fierlinger A, Niazi F, Christensen R. Clinical benefit of intra-articular saline as a comparator in clinical trials of knee osteoarthritis treatments: A systematic review and meta-analysis of randomized trials. Semin Arthritis Rheum. 2016;46(2):151-9.

50. Yazici Y, Tambiah J, Swearingen C, Kennedy S, Strand V, Cole B, et al. Comparison of intra-articular sham and vehicle injection from a phase $2 \mathrm{~b}$ trial of SM04690, a small-molecule Wnt inhibitor, for knee osteoarthritis. 2019 OARSI World Congress on Osteoarthritis; Toronto. Canada. 2019-05-02 to 2019-05-05. Osteoarthr Cartil. https://www.oarsijournal.com/article/ S1063-4584(19)30648-X/fulltext\#relatedArticles2019:S241-S2.

51. Wheaton AJ, Borthakur A, Shapiro EM, Regatte RR, Akella SV, Kneeland $J B$, et al. Proteoglycan loss in human knee cartilage: quantitation with sodium MR imaging--feasibility study. Radiology. 2004;231(3):900-5.

52. Leung A, Liew D, Lim J, Page C, Boukris-Sayag V, Mundae M, et al. The effect of joint aspiration and corticosteroid injections in osteoarthritis of the knee. Int J Rheum Dis. 2011;14(4):384-9.

53. Maricar N, Parkes MJ, Callaghan MJ, Felson DT, O'Neill TW. Do Clinical Correlates of Knee Osteoarthritis Predict Outcome of Intraarticular Steroid Injections? J Rheumatol. 2020;47(3):431-40.

\section{Publisher's Note}

Springer Nature remains neutral with regard to jurisdictional claims in published maps and institutional affiliations.

Ready to submit your research? Choose BMC and benefit from:

- fast, convenient online submission

- thorough peer review by experienced researchers in your field

- rapid publication on acceptance

- support for research data, including large and complex data types

- gold Open Access which fosters wider collaboration and increased citations

- maximum visibility for your research: over $100 \mathrm{M}$ website views per year

At BMC, research is always in progress.

Learn more biomedcentral.com/submissions 